\title{
An extrapyramidal choreiform syndrome caused by amphetamine addiction
}

\author{
H L U N D H A N D K T U N VING \\ From the Departments of Neurology and Psychiatric Research, University of Lund, Sweden
}

SUMMARY Four cases are described to demonstrate the extrapyramidal clinical syndrome sometimes appearing in chronic amphetamine users. The symptoms are dominated by choreiform or athetoid movements, ataxia and disturbances of gait. The syndrome develops during amphetamine abuse and may be observed also during abstinence. The symptoms usually disappear within a week when the drug is discontinued, but may remain for years.

The mental symptoms, including psychosis, caused by amphetamine intoxication are well-known, ${ }^{1}$ but neurological side-effects sometimes appearing are much less recognised. Choreo-athetoid movements caused by high doses of amphetamine have been mentioned in the literature ${ }^{2}{ }^{3}$ and a "jerking syndrome" was reported by Rylander. ${ }^{4}$ We give a more comprehensive description of this syndrome and point out that it may remain for years after finishing drug abuse.

\section{Case reports}

\section{Case 1}

A man, now aged 27 years, during the period 19711977 injected himself intravenously with high doses (gram doses) of amphetamine one to four times a day except for short periods of abstinence. A few months after starting to inject amphetamine he suffered from more or less constant grinding of his teeth and involuntary choreiform movements of his face around his mouth. Only a few months later he developed generalised choreiform and athetoid movements of arms, legs and body. His gait was markedly disturbed, his legs flung erratically and irregularly sideways, there were constant large and small involuntary movements of his arms, and different parts of his body rapidly jerked from side to side and forwards and backwards. Quick choreiform movements dominated, but he also

Address for reprint requests: Dr H Lundh, Department of Neurology, University Hospital, S-221 85 Lund, Sweden.

Accepted 18 May 1981 showed slower more athetoid movements of his trunk, arms and fingers. The strong reeling involuntary movements of the trunk rendered a dancing or drunken appearance to the gait and the patient was known as "the screw." Symptoms were more pronounced just after an injection of amphetamine but did not disappear during periods of abstinence. When performing voluntary motor activities like the fingernose or heel-knee test the involuntary movements diminished and the patient could play different sorts of ballgames.

After he stopped amphetamine abuse the involuntary movements gradually diminished but not until 1978, a year afterwards, did they decrease markedly. Three years afterwards, in 1980, the patient still suffered from teeth grinding and involuntary grimacing of his face. Apart from this his motor performance and gait now is normal.

Case 2

At the age of 20 years this man began to abuse amphetamine and during the following 4-5 years intermittently injected several grams of amphetamine intravenously daily for periods of one to several weeks. At the age of 24 years he stopped using amphetamine and changed to morphine. He claimed he changed because of adverse reactions after amphetamine injections. During his period as an amphetamine addict he was admitted twice to the psychiatric ward for detoxification. Each time he showed dramatic extrapyramidal symptoms. His gait was markedly ataxic and he could not walk straight forward but constantly pushed against the walls of the corridor, his legs vigorously jerking irregularly and his arms performing large, abrupt, rapid ballistic movements like 
the arms of a windmill. His head moved abruptly and irregularly in all directions. He was treated by large intravenous doses of biperiden hydrochloride (Akineton) and haloperidol but his involuntary movements continued, and 48 hours passed before he could sleep. His involuntary movements almost disappeared during sleep. Within a week his involuntary movements diminished and, finally, vanished completely.

\section{Case 3}

This man was admitted to the ward at the age of 20 years after one year of continuous intravenous abuse of large doses of amphetamine. He was hyperactive and unable to sit or stand and continually changed his position. There were almost continuous choreiform movements of his facial muscles, body, arms and legs. The patient's gait was wide-based and obviously ataxic, being fast and stiff with rapid jerking movements somewhat like an actor in a fast moving film resembling the gait seen in Huntington's chorea. This patient was treated orally by central cholinergic blocking drugs (the atropine group of drugs), and became almost free of symptoms. A month after admission to the ward he ran away and again injected amphetamine, but he soon returned with an exacerbation of choreiform movements. In the following years the patient had several relapses of drug abuse and every time the neurological symptoms reappeared. Finally he stopped drug abuse and after that the choreiform movements gradually decreased and disappeared entirely after more than a year.

\section{Case 4}

This man, now aged 35 years, from 1965 to 1972 almost continuously took amphetamine by mouth at a dose of about 0.3 gram two or three times a day. During that time he suffered from general hyperactivity with stereotyped, compulsive behaviour such as repetitively buttoning and unbuttoning his jacket or tidying up over and over again, i.e. punding. ${ }^{4}$ From 1972 to 1977 the patient took amphetamine intravenously in high doses (about one gram per injection). After daily injections for six months continuous jerking involuntary movements of arms and legs began, most pronounced in proximal muscles, together with involuntary grinding of his teeth. On several occasions there were short episodes of spasmodic torticollis which always disappeared when treated with diazepam. His choreiform movements continued even during periods of drug abstinence for weeks or months and did not diminish when the patient did not inject amphetamine for one year 1977-1978. He had a short relapse into abuse in 1978 , but after that he has not used drugs for three years. Since 1978 his involuntary movements have diminished but not disappeared. They are temporarily suppressed by voluntary movements and do not interfere with fine motor activity and disappear during sleep. They are less pronounced when the patient is calm and relaxed and become more obvious when he is tired or nervous. In 1980 this patient was treated with flupenthixol chloride (a neuroleptic drug) at the low dosage of $1 \mathrm{mg}$ three times a day without obvious effect on the choreiform movements. Sedative drugs of different kinds had a positive effect. Computed tomography of the head in 1980 was normal.

\section{Discussion}

These case reports describe the choreatic syndrome sometimes appearing in amphetamine addicts. Besides the choreo-athetoid movements described by Rylander ${ }^{4}$ this extrapyramidal syndrome includes ataxia and abnormal gait of ten resembling the gait seen in Huntington's chorea. Usually these symptoms were most obvious for the first days after admission to the ward and generally disappeared within a week of abstinence as in case 2 . However, as demonstrated by our other cases these choreiform movements may persist for long periods, perhaps indefinitely, after stopping drug abuse. It is of interest that in animals amphetamine is known to cause stereotyped movements ${ }^{5-\tau}$ resembling the so-called punding of amphetamine addicts, ${ }^{4}$ but also obvious choreiform movements. ${ }^{8}$ This is attributed to increased release of dopamine, ${ }^{5}$ and the same pathophysiological mechanism may be operating in humans. Since dopamine receptor blocking drugs are used in the acute treatment of amphetamine abuse, it is possible that such drugs contribute to the fast disappearance of neurological symptoms in most cases. However, we observed no beneficial effect on the extrapyramidal symptoms persisting for years in former amphetamine addicts. In these cases, it is probable that amphetamine has induced plasticity changes of synaptic transmission in parts of the brain controlling extrapyramidal movements. Computed tomography showed no abnormality although amphetamine might cause cerebrovascular accidents. ${ }^{19}$

\section{References}

1 Gunne L-M. Effects of amphetamines in humans. Handbook of Experimental Pharmacology 1977; 45/II:247-75.

2 Bonhoff G, Lawrenz H. Uber Weckamine. Heidelberg: Springer 1954.

3 Mattson R, Calvery JR. Dextroamphetaminesulfate-induced dyskinesias. JAMA 1968; 204: 108-10.

4 Rylander G. Psychoses and the punding and choreiform syndromes in addiction to central stimulant drugs. Psychiat Neurol Neurochir (Amsterdam) 1972; 75:203-12.

5 Randrup A, Munkvad I. Biochemical, anatomical and psychological investigations of stereotyped 
behaviour induced by amphetamines. In: Costa $\mathrm{E}$, Garattini $\mathrm{S}$, eds. Amphetamines and related compounds. New York: Raven Press 1970; 693713.

6 Ellinwood EH. Behavioral and EEG changes in the amphetamine model of psychosis. In: Usdin E, ed. Neuropsychopharmacology of monoamines and their regulatory enzymes. New York: Raven Press 1974; 281-97.

7 Hitzemann RJ, Tseng LF, Hitzemann BA, Sampath-Khanna S, Loh HH. Effects of with- drawal from chronic amphetamine intoxication on exploratory and stereotyped behavior in the rat. Psychopharmacol 1977; 54:295-302.

8 Randrup A, Munkvad I. Stereotyped activities produced by amphetamine in several animal species and man. Psychopharmacologia (Berlin) 1967; 11:300-10.

9 Delaney $P$, Estes $M$. Intracranial hemorrhage with amphetamine abuse. Neurology (Minneap) 1980; 30:1125-8. 